ISSN 0103-5150

Fisioter. Mov., Curitiba, v. 30, n. 2, p. 413-422, Apr./June 2017

Licenciado sob uma Licença Creative Commons

DOI: http://dx.doi.org/10.1590/1980-5918.030.002.AR04

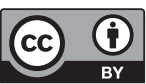

\title{
High-velocity low-amplitude manipulation (thrust) and athletic performance: a systematic review
}

\author{
Manipulação em alta velocidade/baixa amplitude e \\ desempenho atlético: uma revisão sistemática
}

\section{Mikhail Santos Cerqueira ${ }^{[a]}$, Rafael Moreira Sales ${ }^{[a]}$, Cláudia Thais Pereira Pinto ${ }^{[b]}$, Bruno Gonçalves Dias Moreno ${ }^{[c]}$, Alberto Galvão de Moura Filho ${ }^{[a]}$}

[a] Universidade Federal de Pernambuco (UFPE), Recife, Pernambuco, Brazil

[b] Instituto de Medicina Integral Professor Fernando Figueira (IMIP), Recife, Pernambuco, Brazil

[c] Faculdades Adamantinenses Integradas (UNIFAI), Adamantina, São Paulo, Brazil

\section{Abstract}

Introduction: The high demand level in sports has encouraged the search for strategies to increase the yield. In this context, manual therapy through high-velocity low-amplitude (thrust) has been employed in many sports. Despite the adhesion of manual therapists in clinical practice, there were no systematic reviews on this topic. Objective: To evaluate the effects of thrust on the performance of athletes in relation to the outcomes hand-grip strength, jump height and running speed. Methods: The databases used in the search were MEDLINE / PUBMED, LILACS, CINAHL, PEDro, WEB OF SCIENCE, CENTRAL and SCOPUS, and Randomized controlled trials were included, whose participants were professionals or recreational athletes and had thrust as intervention. The methodological quality of the studies was assessed using the PEDro scale of 10 points. Intervention effects were determined by the mean difference and confidence interval. The data analysis was done in the descriptive form due to the heterogeneity found among studies. Results: Five trials were included with a total of 95 individuals. The methodological quality of studies was low, with an average value of 5.6 on the PEDro scale. It was found two articles for each outcome, but in none of them was presented differences between the experimental and control groups considering the confidence interval. Conclusion: The current evidence is insufficient to determine the use or nonuse the MAVBA in sports in order to improve performance.

Keywords: Musculoskeletal Manipulations. Athletic Performance. Manipulation, Osteopathic.

Manipulation, Chiropractic.

\footnotetext{
MSC: PhD student, e-mail: mikalsantosc@hotmail.com RMS: MS, email: rafaelsalesfisio@gmail.com

CTPP: Master Student, e-mail: cllaudia-thais@hotmail.com

BGDM: PhD, e-mail: bruno@ebrafim.com

AGMF: PhD, e-mail: albertomoura@hotmail.com
}

Fisioter Mov. 2017 Apr/June;30(2):413-22 
Resumo

Introdução: $O$ elevado nível de exigência no meio esportivo tem incentivado a busca por estratégias para aumentar o rendimento. Nesse contexto, a terapia manual através da Manipulação em Alta e Velocidade e Baixa Amplitude (MAVBA) tem sido empregada em vários esportes. Apesar da adesão dos terapeutas manuais na prática clínica, não foram encontradas revisões sistemáticas acerca do tema. Objetivo: Avaliar os efeitos da manipulação de alta velocidade e baixa amplitude sobre o desempenho de atletas. Métodos: As bases de dados utilizadas na busca foram MEDLINE/PUBMED, LILACS, CINAHL, PEDro, WEB OF SCIENCE, CENTRAL $e$ SCOPUS. Foram incluídos Ensaios Randomizados e Controlados, cujos participantes eram atletas profissionais ou recreacionais, que aplicaram a MAVBA como intervenção. A qualidade metodológica dos estudos foi avaliada por meio da Escala PEDro. Os efeitos da intervenção foram determinados através da diferença de média e do respectivo intervalo de confiança (IC). A análise dos dados foi realizada de maneira descritiva, em virtude da heterogeneidade encontrada entre os estudos. Resultados: Cinco ensaios foram incluídos com um total de 95 indivíduos. A qualidade metodológica dos estudos foi baixa, com uma média de 5.6 na Escala de PEDro. Foram encontrados dois artigos para cada desfecho, e em nenhum deles foi detectada diferença entre o grupo experimental e controle quando levado em consideração o IC. Conclusão: A evidência atual é insuficiente para determinar o uso ou o não uso da MAVBA em com objetivo de melhorar o desempenho esportivo.

Palavras-chave: Manipulação Musculoesquelética. Desempenho Atlético. Manipulação Osteopática. Manipulação Quiroprática.

\section{Introduction}

The levels of competitiveness and the ever higher demand in the sports field have entailed an increasing pursuit for alternatives which can improve athletes performance, especially of those who avoid using drugs or undergoing surgery $(1,2)$. To compete at high levels structurally and functionally healthy tissue are required along with a neuromuscular coordination network. These factors directly contribute to a successful athletic career, where characteristics such as endurance, strength, flexibility and proprioception are paramount $(3,4)$.

Among the various tools used in the sports realm, manual treatments come with a wide variety of techniques that can help enhance the athletes' performance. In this context, high-velocity low-amplitude manipulation (thrust) have been used to improve performance in soccer, athletics and golf athletes (5 - 9). This kind of handling is characterized by a fast and short pulse which is applied to the end of the synovial joints range of passive motion (10).

In clinical practice, the thrust is used to control pain, to increase range of motion and spinal facilitation, and it can also enhance muscle strength and activation (11 - 13). The heating and functional optimization of the musculoskeletal structures are other added benefits gleaned from manipulation before competitions which can improve sports performance (14).
Due to the increase in adhesion and use of manual therapy by athletes and sports therapists, respectively, several studies have evaluated the effects of thrust in athletic performance through variables that directly relate to the sporting gesture of each modality, such as: hand-grip strength, height of jump and running speed $(2,15,16)$. However, we have not found systematic reviews that addressed the issue. The objective of this systematic review is to evaluate the effect of thrust on the performance of athletes concerning the outcomes hand-grip strength, jump height and running speed.

\section{Methods}

Study design

The design of this systematic review was developed by utilizing the Preferred Reporting Items of guidelines for Systematic Reviews and Meta-Analyses (PRISMA). The PRISMA statement contains a checklist which was designed to be used as a basis for writing systematic reviews of randomized trials (17).

Identification of studies

A systematic search of the literature was carried out through MEDLINE / PUBMED, LILACS, CINAHL, 
PEDro, WEB OF SCIENCE, CENTRAL and SCOPUS, with no restrictions as for the language and year of publication of the included studies. The following terms were used in isolation or in combination: "Sports", "Sports Medicine", "Athletes", "Athletic Performance", "Athletic Injuries", "Manipulation, Osteopathic", "Manipulation, Chiropractic", "Manipulation, Spinal", "Manipulation, Orthopedic", "Musculoskeletal Manipulations" and "Randomized Controlled Trial".

The last search was conducted on the first day of August 2014 and the search strategies developed for each database are described in Appendix 1. The references of the articles included in order to track other promising, eligible trials were also checked.

The eligibility criteria used in this study are described in Figure 1. Trials with samples not constituted of athletes were not included. The outcomes taken into consideration were: vertical jump height, hand-grip strength and running speed.

\begin{tabular}{l}
$\quad$ Figure 1 - Inclusion Criteria \\
\hline Design \\
* Randomized controlled trials \\
Participants \\
* Professional and recreational athletes \\
Intervention \\
* High-velocity low-amplitude manipulation (thrust) \\
Outcome measures \\
* Hand-grip strength \\
* Vertical jump height \\
* Running speed \\
\hline
\end{tabular}

Study selection

The study selection protocol was composed by the assessment of titles and subsequent abstracts, followed by careful analysis regarding eligibility exacted through the reading of full text. The search was performed by two independent reviewers (R.M.S. and M.S.C.), and if there were disagreement between the two reviewers, the opinion of a third reviewer was requested (A.G.M.F.). The following data which were extracted from the articles included: author (s); year of publication; aims; intervention; control; outcome(s); "follow up"; results; conclusion.

\section{Quality assessment of studies}

The study quality was assessed individually through PEDro scale (18), which displays good levels of validity and reliability $(19-21)$. This scale determines the risk of bias and reports to the statistical procedure utilized in clinical trials. Eleven items are considered on the scale: eligibility criteria; randomization of sample; allocation concealment; similar groups in the "baseline"; blinding of participants; blinding of the therapists; blinding of assessors; measurement of at least one key outcome obtained in over $85 \%$ of subjects initially distributed by groups; intention-to-treat analysis; intergroup comparison; measurement of treatment effect and variability. The first item in the scale (eligibility criteria) was not scored due to its being associated with external validation. The total score varies therefore between 0-10 points. So it is believed that the higher the score, the better the quality of the methodological study. Studies with high risk of bias (score $<6$ ) were considered to be of low methodological quality (22).

Data related to the trial registration, funding, sample size calculation and primary outcome were also extracted. These four items are part of the "CONSORT Statement" and they translate into more transparency and methodological quality (17).

\section{Measurement of outcomes}

Data were extracted for the following outcomes: vertical jump height, hand-grip strength and running speed. To determine the effects of the intervention, the mean difference between the groups and the respective confidence interval $(95 \%)$ were obtained. PEDro Site confidence interval calculator was used when the confidence interval was not shown in the articles.

\section{Data analysis}

Data analysis was performed in a descriptive way due to the heterogeneity between the studies concerning the location where handling was held and sports modality practiced.

To characterize the groups, the variables sport modality, age and sample size were utilized. To characterize the intervention, duration, body area, and technical application of frequency were used. 


\section{Results}

Articles flow throughout the review

The applied search strategy revealed the presence of 259 studies. Of those, only five were eligible for the analysis. The study selection flowchart is shown in Figure 2.

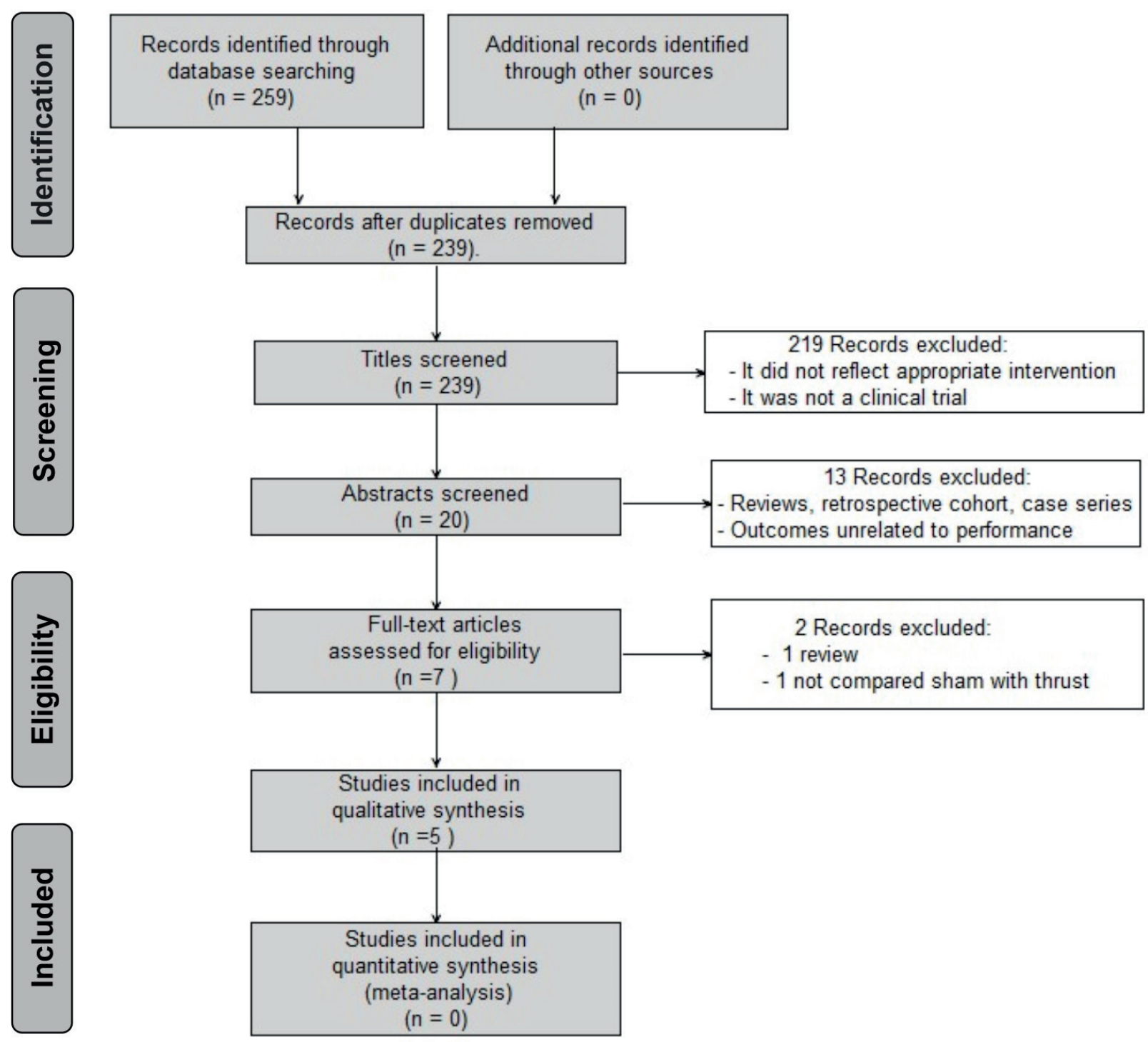

Figure 2 - Flowchart for the inclusion of studies.

\section{Description of studies}

The five articles included were published between the years 2006 and 2014. The sample size ranged from 17 to 24 volunteers. The total sample consisted of 95 individuals of both genders. The description of these studies is presented in Table 1. 
Table 1 - Description of the studies included in the review $(n=5)$

\begin{tabular}{|c|c|c|c|}
\hline Study & Population & Intervention & Comparison \\
\hline Botelho (16) & $\begin{array}{l}\mathrm{n}=18 \text {; Professional judo } \\
\text { practitioners; Average age } \\
\text { of the groups was not } \\
\text { presented. }\end{array}$ & $\begin{array}{l}\text { Thrust cervical in places } \\
\text { with mobility restriction } \\
\text { after evaluation of static and } \\
\text { dynamic mobility. }\end{array}$ & $\begin{array}{c}\text { Sham (Sudden drop of the head with the back } \\
\text { removed). }\end{array}$ \\
\hline Hedlund (23) & $\begin{array}{l}\mathrm{n}=19 \text {; Handball } \\
\text { professional players; } \\
\text { Average age INT: } 22 \text { (SD } \\
\text { 1.6); Average age CON: } \\
17.9 \text { (SD 0.5). }\end{array}$ & $\begin{array}{l}\text { Thrust in tibiotarsal joint } \\
\text { with dysfunction }\end{array}$ & Sham (Contact the distal end of the tibia). \\
\hline Humphries (2) & $\begin{array}{c}\mathrm{n}=24 \text {; Recreational } \\
\text { players Basketball; } \\
\text { Average age INT: } 26 \text { (SD } \\
\text { 8.5); Average age COM: } \\
26.3 \text { (SD 10). }\end{array}$ & $\begin{array}{l}\text { Thrust in the cervical spine } \\
\text { (C5 - C6). }\end{array}$ & $\begin{array}{c}\text { Sham (cervical rotation through the Activator } \\
\text { instrument). }\end{array}$ \\
\hline Sandell (6) & $\begin{array}{l}\mathrm{n}=17 \text {; Professional } \\
\text { athletics; Average age of } \\
\text { groups not displayed. }\end{array}$ & $\begin{array}{l}\text { Thrust the sacroiliac joints } \\
\text { and hip, depending on the } \\
\text { assessment of mobility. }\end{array}$ & $\begin{array}{l}\text { Sham (thrust without eliciting the cavitation effect - } \\
\text { sound of "click"). }\end{array}$ \\
\hline Shrier (15) & $\begin{array}{l}\mathrm{n}=17 \text {; Professional } \\
\text { runners; Average age of } \\
\text { groups not displayed. }\end{array}$ & $\begin{array}{l}\text { Thrust applied in the lower } \\
\text { back, thoracolumbar and } \\
\text { lower limbs depending on the } \\
\text { mobility assessment. }\end{array}$ & $\begin{array}{l}\text { Sham (EMG electrodes were placed on the limbs } \\
\text { and it was made known that they had the purpose } \\
\text { of increasing energy and strength). }\end{array}$ \\
\hline
\end{tabular}

Note: n: sample size; CON: control; SD: Standard Deviation; INT: intervention; thrust: High-velocity low-amplitude manipulation.

Table 2 - Methodological quality of eligible studies $(n=5)$

\begin{tabular}{|c|c|c|c|c|c|c|c|c|c|c|c|c|c|c|c|c|}
\hline \multirow[t]{2}{*}{ Study } & \multicolumn{11}{|c|}{ PEDro scale items } & \multirow{2}{*}{$\begin{array}{l}\text { PEDro } \\
\text { score } \\
(0-10)\end{array}$} & \multirow[t]{2}{*}{ Registered } & \multirow{2}{*}{$\begin{array}{c}\text { Outcome } \\
\text { Primary } \\
\text { stated }\end{array}$} & \multirow[t]{2}{*}{ Funded } & \multirow{2}{*}{$\begin{array}{c}\text { Sample size } \\
\text { calculation } \\
\text { presented }\end{array}$} \\
\hline & 1 & 2 & 3 & 4 & 5 & 6 & 7 & 8 & 9 & 10 & 11 & & & & & \\
\hline Botelho (16) & S & S & N & $S$ & $S$ & $\mathrm{~N}$ & N & S & S & S & $\mathrm{N}$ & 6 & S & S & $\mathrm{N}$ & N \\
\hline Hedlund (23) & $S$ & S & N & $S$ & N & N & $S$ & N & N & $S$ & $\mathrm{~N}$ & 4 & $S$ & $S$ & S & S \\
\hline Humphries (2) & $S$ & S & N & $S$ & $S$ & N & $S$ & S & S & $S$ & $\mathrm{~N}$ & 7 & $\mathrm{~N}$ & $S$ & $\mathrm{~N}$ & N \\
\hline Sandell (6) & $S$ & S & $S$ & $S$ & N & N & S & S & S & $S$ & $S$ & 8 & N & S & $\mathrm{N}$ & N \\
\hline Shrier (15) & $S$ & S & $\mathrm{N}$ & S & $\mathrm{N}$ & $\mathrm{N}$ & $\mathrm{N}$ & $\mathrm{N}$ & $\mathrm{N}$ & $S$ & $\mathrm{~N}$ & 3 & $\mathrm{~N}$ & $S$ & $\mathrm{~N}$ & S \\
\hline
\end{tabular}

Note: S: Yes; N: no.

a 1: eligibility criteria and source of participants; 2: random allocation; 3: concealed allocation; 4: baseline comparability; 5: blinded participants; 6: blinded therapists; 7: blinded assessors; 8: Adequate follow-up; 9:intention-to-treat analysis; 10: between-group comparison; 11: point estimates and variability.

a Item 1 does not contribute to total score. 
Quality

The methodological quality of eligible articles are displayed in Table 2 . The total score according to PEDro scale ranged from 3-8, with an average of 5.6 points. All articles met the requirements for sample randomization, similarity between the groups in the "baseline" and the carrying out of intergroup comparison. The less often fulfilled items were the ones related to blinding of the therapists and allocation concealment. The registry was observed in two trials $(15,23)$, sample size calculation was performed in two articles $(15,23)$, and one study received funding (23).

\section{Participants}

There was some variability among the sports performed in the included articles: judo (6); handball (23); Basketball (2); athletics $(6,15)$. Three studies $(6,15,16)$ failed to show the average age of the volunteers, making it impossible to trace the general profile of the sample with respect to this variable.

\section{Interventions}

The region of the body where thrust was applied varied between the selected articles. In studies with the outcome hand-grip strength, manipulation was utilized on the cervical region $(2,16)$. As for the tests with the vertical jump outcome, in the Hedlund et al. study (23), the technique was applied on the tibiotarsal joint, while Shrier, Macdonald and Uchacz (15) directed the intervention to the lower back, thoracic spine and / or legs, choice to be made depending on the assessment. The manipulation of the sacroiliac and hip joints was carried out in the study by Sandell, Palmgren and Björndah (6) which produced as an outcome the running speed, similar to those of Shrier's, Macdonald's and Uchacz's (15), previously described.

\section{Measurement of outcomes}

Hand-grip strength was measured by Hydraulic Dynamometers $(2,16)$, and the vertical jump height was measured by an infrared optoelectronic system (23). On the other hand, running speed was measured through Running Tests of 30 and 40 meters utilizing photocells $(6,15)$.
Effects of thrust on the hand-grip strength

Two articles verified the effects of thrust on the hand-grip strength $(2,16)$, with a total sample of 42 participants. There was no difference in hand-grip strength after the intervention, between the experimental and control groups, when analyzing the mean difference (2.8 kgf) and the confidence interval (-11.5 to 5.90) in the study by Humphries et al (2).

Botelho and Andrade's result (16) also points out that there was no difference between the strength in the placebo and intervention groups. Although the authors conclude that there was an increase in the average power in favor of the intervention group, the confidence interval values indicate that there were no differences between groups (Sham or thrust) after intervention. It should be noted that in this study the authors assessed hand-grip strength in three varying moments after intervention in both arms, and the extent of a greater average increase strength in favor of the intervention group $(2.73 \mathrm{kgf}$ in the second measure of the left arm), the confidence interval values $(-13.58$ to 9.68$)$ are indicative that this result must not be considered significant.

\section{Effects of thrust on vertical jump height}

Two articles assessed the effects of thrust on vertical jump height compared to Sham groups $(15,23)$, with a total of 36 volunteers enrolled. According to Hedlund et al. (23) the thrust can increase the height of the jump, but for Shrier, Macdonald and Uchacz (15) the effect of thrust on jump height in the analyzed athletes is inconclusive. Looking at the difference between the intervention and Sham conditions, it can safely be assured that there was no difference in the height of jumps between the groups in the first study (mean difference of $0.47 \mathrm{~cm}$ with a confidence interval -1.31 to 2.26), there was even a decrease in jump height in the second study (mean difference of $0.9 \mathrm{~cm}$ with a confidence interval of -0.9 to 2.8).

\section{Effects of thrust on the running speed}

Two articles analyzed the effects of thrust on the running speed, with a total of 34 volunteers enrolled $(6,15)$. The running speed, which was estimated according to the time it takes to cover a certain distance, was higher (mean difference of 0.062 seconds with a confidence interval 0.00 
to 0.13 ) in the experimental group in the study by Sandell, Palmgren and Björndahl (6). Despite the mean differences observed it can be seen by the confidence interval that the result is not indicative of significance. In the study by Shrier, Macdonald and Uchacz (15) the mean difference between the groups was -0.02 seconds (confidence interval -0.07 to 0.05 ), which is a non-significant result of the intervention. The results and conclusion of all studies are presented in Table 3.

Table 3 - Results and conclusions of studies analyzing the effects of thrust in athletic performance $(n=5)$

\begin{tabular}{|c|c|c|c|}
\hline $\begin{array}{l}\text { Study and } \\
\text { Modality }\end{array}$ & Follow-up & Outcomes and results & Conclusions \\
\hline $\begin{array}{l}\text { Botelho (16) } \\
\text { (Judo) }\end{array}$ & $\begin{array}{l}20 \text { seconds after the } \\
\text { intervention }\end{array}$ & $\begin{array}{l}\text { Hand-grip strength: The highest DM of } \\
6 \text { measurements in the evaluation was } \\
2,073 \text { kgf (2nd measured in the left } \\
\text { arm) in favor of thrust group ( } 95 \% \mathrm{Cl} \\
-13.58 \text { to 9.68). }\end{array}$ & $\begin{array}{l}\text { Author: Thrust increases judo athletes' hand- } \\
\text { grip strength. } \\
\text { Review: Thrust did not increase hand-grip } \\
\text { strength of judo athletes (there was no } \\
\text { difference between experimental and control } \\
\text { groups when evaluated IC). }\end{array}$ \\
\hline $\begin{array}{l}\text { Hedlund (23) } \\
\text { (Handball) }\end{array}$ & $\begin{array}{l}3 \text { weeks after the first of } \\
\text { three interventions. }\end{array}$ & $\begin{array}{l}\text { Jump height: } 0.47 \mathrm{~cm} \mathrm{AD} \text { in favor of the } \\
\text { thrust group ( } 95 \% \mathrm{Cl}-1.31 \text { to } 2.26) \text {. }\end{array}$ & $\begin{array}{l}\text { Author: Can increase vertical jump height } \\
\text { Handball players. } \\
\text { Review: Thrust did not increase vertical jump } \\
\text { height in Handball players (there was no } \\
\text { difference between experimental and control } \\
\text { groups). }\end{array}$ \\
\hline $\begin{array}{l}\text { Humphries (2) } \\
\text { (Basketball) }\end{array}$ & $\begin{array}{l}\text { Immediately following } \\
\text { the intervention }\end{array}$ & $\begin{array}{l}\text { Handgrip strength: AD } 2.8 \mathrm{kgf} \text { in favor } \\
\text { of the THRUST group }(95 \% \mathrm{Cl}-11.5 \text { to } \\
5.90) \text {. }\end{array}$ & $\begin{array}{l}\text { Author: Unilateral thrust in low neck did not } \\
\text { improve the yield of basketball players. } \\
\text { Review: Unilateral thrust in low neck did not } \\
\text { improve the yield of basketball players. }\end{array}$ \\
\hline $\begin{array}{l}\text { Sandell (6) } \\
\text { (Runners) }\end{array}$ & Not Specified & $\begin{array}{l}\text { Running speed: } A D 0.062 \text { seconds } \\
\text { (improved) in favor of thrust group } \\
(95 \% \mathrm{Cl} 0.00 \text { to } 0.13) \text {. }\end{array}$ & $\begin{array}{l}\text { Author: It was not proven positive effect of } \\
\text { thrust on the running speed. } \\
\text { Review: It was not proven positive effect of } \\
\text { thrust on the running speed. }\end{array}$ \\
\hline $\begin{array}{l}\text { Shrier (15) } \\
\text { (Runners) }\end{array}$ & $\begin{array}{l}48 \text { hours after the } \\
\text { procedures }\end{array}$ & $\begin{array}{l}\text { Jump Height: AD } 0.9 \mathrm{~cm} \text { (worsened) in } \\
\text { favor of the sham group ( } 95 \% \mathrm{Cl}-0.9 \text { to } \\
\text { 2.8). Running speed: Difference }-0.02 \\
\text { seconds (improved) for the THRUST } \\
\text { group }(95 \% \mathrm{Cl}-0.07 \text { to } 0.05) \text {. }\end{array}$ & $\begin{array}{l}\text { Author: Grande variability the vertical jump test } \\
\text { and "Sprint" led to inconclusive results. } \\
\text { Review: The intervention was not effective } \\
\text { and adverse effects in } 3 \text { subjects should be } \\
\text { considered. }\end{array}$ \\
\hline
\end{tabular}

Note: AD: Average difference; Cl: Confidence interval; INT: Intervention; thrust: High-velocity low-amplitude manipulation.

\section{Discussion}

This systematic review aimed to synthesize and critically analyze the current available evidence on the effects of thrust on the performance of professional and recreational athletes. All items included in this study estimated the effects of thrust compared to Sham $(2,6,15,16,23)$. Overall, there was no difference between the experimental and control groups. When the comparison results between the thrust and Sham groups reached a value of $\mathrm{p}<$
0.05 , the confidence intervals of values exceeded the nullity line, indicating that these differences were not significant.

The studies methodological quality was low on average, when analysis on the risk of bias was taken into consideration, with two of the articles included with scoring less than six in PEDro Scale $(15,23)$ and other with score of six $(16)$. Despite the importance of trial registration, it turned out only two studies performed this procedure (16, 23 ) and of the five articles included two reported 
with a certain degree of transparency how sample calculation was carried out $(15,23)$. In addition, important topics such as location concealment and Measurement of Treatment Effect and variability have been reported in only one study (6).

The search strategy utilized, in addition to database search tracked the references of the articles included in order to find potentially eligible studies. The search, therefore, identified the most controlled clinical trials which addressed the effects of thrust on athletic performance.

This study is probably the first systematic review that assesses the effects of thrust on outcomes directly related to athletes' performance. The results show that the available evidence bears no sufficient methodological quality to support the use or not of the intervention in this population. A wide range of sports modalities and technical application areas were found in the articles, which once added to the small amount of articles included limit the results interpretation.

\section{Conclusion}

Although thrust is widely used in sports in order to improve performance, current evidence is insufficient to determine the use or nonuse this intervention. Clinical trials with greater methodological rigor and with the largest number of volunteers is needed to allow for more consistent inferences about the effects of MAVBA performance athletes.

\section{Acknowledgment}

Coordination for the Improvement of High Level (CAPES, Brazil).

\section{References}

1. Stump JL, Redwood D. The use and role of sport chiropractors in the national football league: a short report. J Manipulative Physiol Ther. 2002;25(3):A2-A5.

2. Humphries KM, Ward J, Coats J, Nobert J, Amonette W, Dyess S. Immediate effects of lower cervical spine manipulation on handgrip strength and free-throw accuracy of asymptomatic basketball players: A pilot study. J Chiropr Med. 2013;12(3):153-9.
3. Mori S, Ohtani Y, Imanaka K. Reaction times and anticipatory skills of karate athletes. Hum Mov Sci. 2002;21(2):213-30.

4. Gunnar Brolinson P, McGinley SMG, Kerger S. Osteopathic manipulative medicine and the athlete. Curr Sports Med Rep. 2008;7(1):49-56.

5. Santilli V, Beghi E, Finucci S. Chiropractic manipulation in the treatment of acute back pain and sciatica with disc protrusion: a randomized double-blind clinical trial of active and simulated spinal manipulations. Spine J. 2006; 6(2):131-7.

6. Sandell J, Palmgren PJ, Björndahl L. Effect of chiropractic treatment on hip extension ability and running velocity among young male running athletes. J Chiropr Med. 2008;7(2):39-47.

7. Wilkey A, Gregory M, Byfield D, McCarthy PW. A comparison between chiropractic management and pain clinic management for chronic low-back pain in a national health service outpatient clinic. J Altern Complement Med. 2008;14(5):465-73.

8. Brolinson PG, Smolka M, Rogers M, Sukpraprut S, Goforth MW, Tilley G, et al. Precompetition manipulative treatment and performance among Virginia Tech athletes during 2 consecutive football seasons: a preliminary, retrospective report. J Am Osteopath Assoc. 2012;112(9):607-15.

9. Costa SM V, Chibana YET, Giavarotti L, Compagnoni DS, Shiono AH, Satie J, et al. Effect of spinal manipulative therapy with stretching compared with stretching alone on full-swing performance of golf players: a randomized pilot trial. J Chiropr Med. 2009;8(4):165-70.

10. Evans DW. Mechanisms and effects of spinal highvelocity, low-amplitude thrust manipulation: previous theories. J Manipulative Physiol Ther. 2002;25(4):251-62.

11. Colloca CJ, Keller TS. Electromyographic reflex responses to mechanical force, manually assisted spinal manipulative therapy. Spine. 2001;26(10):1117-24.

12. Dishman JD, Ball KA, Burke J. First Prize: Central motor excitability changes after spinal manipulation: a transcranial magnetic stimulation study. J Manipulative Physiol Ther. 2002;25(1):1-9. 
13. Hillermann B, Gomes AN, Korporaal C, Jackson D. A pilot study comparing the effects of spinal manipulative therapy with those of extra-spinal manipulative therapy on quadriceps muscle strength. J Manipulative Physiol Ther. 2006;29(2):145-9.

14. Brolinson PG. Precompetition manipulation: placebo or performance enhancer? Clin J Sport Med. 2003;13(2):69-70.

15. Shrier I, Macdonald D, Uchacz G. A pilot study on the effects of pre-event manipulation on jump height and running velocity. Br J Sports Med. 2006;40(11):947-9.

16. Botelho MB, Andrade BB. Effect of cervical spine manipulative therapy on judo athletes' grip strength. J Manipulative Physiol Ther. 2012;35(1):38-44.

17. Moher D, Hopewell S, Schulz KF, Montori V, Gøtzsche PC, Devereaux PJ, et al. CONSORT 2010 Explanation and Elaboration: Updated guidelines for reporting parallel group randomised trials. BMJ. 2010;340:c869. 2010;63(8):e1-37.

18. Sherrington C, Herbert RD, Maher CG, Moseley AM. PEDro. A database of randomized trials and systematic reviews in physiotherapy. Man Ther. 2000;5(4):223-6.

19. Maher CG, Sherrington C, Herbert RD, Moseley AM, Elkins M. Reliability of the PEDro scale for rating quality of randomized controlled trials. Phys Ther. 2003;83(8):713-21.
20. Macedo LG, Elkins MR, Maher CG, Moseley AM, Herbert RD, Sherrington C. There was evidence of convergent and construct validity of Physiotherapy Evidence Database quality scale for physiotherapy trials. J Clin Epidemiol. 2010;63(8):920-5.

21. Shiwa SR, Costa LOP, Costa L da CM, Moseley A, Hespanhol Junior LC, Venâncio R, et al. Reproducibility of the Portuguese version of the PEDro Scale. Cadernos de Saúde Pública. 2011. p. 2063-8.

22. Parreira P do CS, Costa L da CM, Hespanhol Junior LC, Lopes AD, Costa LOP. Current evidence does not support the use of Kinesio Taping in clinical practice: A systematic review. J Physiother. 2014;60(1):31-9.

23. Hedlund S, Nilsson H, Lenz M, Sundberg T. Effect of chiropractic manipulation on vertical jump height in young female athletes with talocrural joint dysfunction: A single-blind randomized clinical pilot trial. J Manipulative Physiol Ther. 2014;37(2):116-23.

Received in 03/28/2016 Recebido em 28/03/2016

Approved in 03/02/2017 Aprovado em 02/03/2017 


\section{Appendix 1 - Search Strategies}

MEDLINE/PUBMED

((("Sports"[Mesh] OR "Sports Medicine"[Mesh]) OR "Athletes"[Mesh]) OR "Athletic Performance"[Mesh]) OR "Athletic Injuries"[Mesh] AND ("Manipulation, Osteopathic"[Mesh] OR "Manipulation, Chiropractic"[Mesh] OR "Manipulation, Spinal"[Mesh] OR "Manipulation, Orthopedic"[Mesh] OR "Musculoskeletal Manipulations"[Mesh]) AND Randomized Controlled Trial[ptyp].

LILACS

(mh:((mh:("sports")))) AND (mh:( (mh:("manipulation, Osteopathic")))). (mh:((mh:("sports")))) AND (mh:( (mh:("manipulation, Chiropractic")))). (mh:((mh:("sports")))) AND (mh:( (mh:("manipulation, Orthopedic")))). (mh:((mh:("sports")))) AND (mh:( (mh:("manipulation, Spinal")))). (mh:((mh:("sports")))) AND (mh:( (mh:("Musculoskeletal Manipulations")))).

(mh:((mh:("sports medicine")))) AND (mh:( (mh:("Manipulation, osteopathic")))). (mh:((mh:("sports medicine")))) AND (mh:( (mh:("Manipulation, Chiropractic")))). (mh:((mh:("sports medicine"))) AND (mh:( (mh:("Manipulation, orthopedic")))). (mh:((mh:("sports medicine")))) AND (mh:( (mh:("Manipulation, Spinal")))).

(mh:((mh:("sports medicine")))) AND (mh:( (mh:("Musculoskeletal Manipulations")))).

(mh:((mh:("Athletes")))) AND (mh:( (mh:("Manipulation, osteopathic")))). (mh:((mh:("Athletes")))) AND (mh:( (mh:("Manipulation, Chiropractic")))). (mh:((mh:("Athletes")))) AND (mh:( (mh:("Manipulation, Orthopedic")))). (mh:((mh:("Athletes")))) AND (mh:( (mh:("Manipulation, Spinal")))). (mh:((mh:("Athletes")))) AND (mh:( (mh:("Musculoskeletal Manipulations")))).

(mh:((mh:("Athletic Performance")))) AND (mh:( (mh:("Manipulation, Osteopathic")))). (mh:((mh:("Athletic Performance"))) AND (mh:( (mh:("Manipulation, Chiropractic")))).
(mh:((mh:("Athletic Performance")))) AND (mh:( (mh:("Manipulation, Orthopedic")))). (mh:((mh:("Athletic Performance")))) AND (mh:( (mh:("Manipulation, Spinal")))). (mh:((mh:("Athletic Performance")))) AND (mh:( (mh:("Musculoskeletal Manipulations")))).

(mh:((mh:("Athletic Injuries")))) AND (mh:( (mh:("Manipulation, osteopathic")))). (mh:((mh:("Athletic Injuries")))) AND (mh:( (mh:("Manipulation, Chiropractic")))). (mh:((mh:("Athletic Injuries")))) AND (mh:( (mh:("Manipulation, Orthopedic")))). (mh:((mh:("Athletic Injuries")))) AND (mh:( (mh:("Manipulation, spinal")))). (mh:((mh:("Athletic Injuries")))) AND (mh:( (mh:("Musculoskeletal Manipulations")))).

\section{CINAHL}

(athletes OR sports OR sports medicine OR athletic performance) AND (osteopathic manipulation OR chiropractic manipulation OR Manipulation Orthopedic OR Manipulation Spinal OR Musculoskeletal Manipulations) and (Randomized Controlled Trials).

PEDro

(manipulation and athletes)

WEB OF SCIENCE

(athletes OR sports OR sports medicine OR athletic performance) AND (osteopathic manipulation OR chiropractic manipulation OR Manipulation Orthopedic OR Manipulation Spinal OR Musculoskeletal Manipulations) and (Randomized Controlled Trials).

\section{CENTRAL}

(athletes OR sports OR sports medicine OR athletic performance) AND (osteopathic manipulation OR chiropractic manipulation OR Manipulation Orthopedic OR Manipulation Spinal OR Musculoskeletal Manipulations).

\section{SCOPUS}

((athletes OR sports OR sports medicine OR athletic performance) AND (osteopathic manipulation OR chiropractic manipulation OR manipulation orthopedic OR manipulation spinal OR musculoskeletalmanipulations)). 